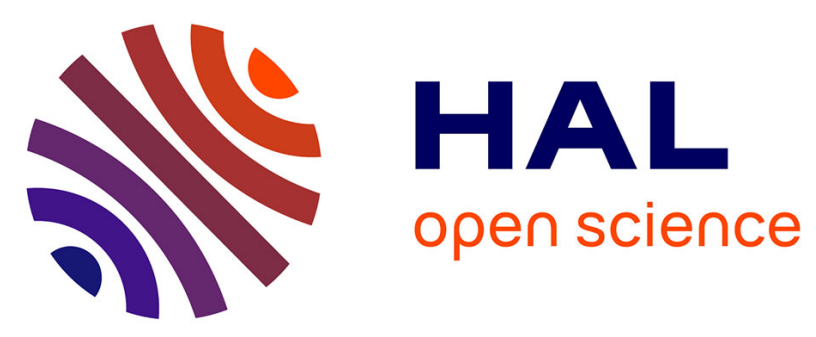

\title{
Non-achievement of LDL-cholesterol targets in patients with diabetes at very-high cardiovascular risk receiving statin treatment: Incidence and risk factors
}

\author{
Cyril Breuker, Florian Clement, Thibault Mura, Valérie Macioce, Audrey
} Castet-Nicolas, Yohan Audurier, Catherine Boegner, Emilie Morcrette, Anne Jalabert, Maxime Villiet, et al.

\section{To cite this version:}

Cyril Breuker, Florian Clement, Thibault Mura, Valérie Macioce, Audrey Castet-Nicolas, et al.. Nonachievement of LDL-cholesterol targets in patients with diabetes at very-high cardiovascular risk receiving statin treatment: Incidence and risk factors. International Journal of Cardiology, 2018, 268, pp.195 - 199. 10.1016/j.ijcard.2018.04.068 . hal-01849461

\section{HAL Id: hal-01849461 \\ https://hal.umontpellier.fr/hal-01849461}

Submitted on 4 Jan 2020

HAL is a multi-disciplinary open access archive for the deposit and dissemination of scientific research documents, whether they are published or not. The documents may come from teaching and research institutions in France or abroad, or from public or private research centers.
L'archive ouverte pluridisciplinaire HAL, est destinée au dépôt et à la diffusion de documents scientifiques de niveau recherche, publiés ou non, émanant des établissements d'enseignement et de recherche français ou étrangers, des laboratoires publics ou privés. 


\title{
Non-achievement of LDL-cholesterol targets in patients with diabetes at very-high cardiovascular risk receiving statin treatment: Incidence and risk factors
}

\author{
Cyril Breuker ${ }^{\mathrm{a}, \mathrm{b}, *, 1,2}$, Florian Clement ${ }^{\mathrm{a}, 1,2}$, Thibault Mura ${ }^{\mathrm{c}, 2}$, Valérie Macioce ${ }^{\mathrm{c}, 2}$, Audrey Castet-Nicolas ${ }^{\mathrm{a}, \mathrm{e}, 2}$, \\ Yohan Audurier ${ }^{\mathrm{a}, 2}$, Catherine Boegner ${ }^{\mathrm{d}, 2}$, Emilie Morcrette ${ }^{\mathrm{d}, 2}$, Anne Jalabert ${ }^{\mathrm{a}, 2}$, Maxime Villiet ${ }^{\mathrm{a}, 2}$, \\ Antoine Avignon ${ }^{\mathrm{b}, \mathrm{d}, \mathrm{C}, 2}$, Ariane Sultan $\mathrm{b}, \mathrm{d}, \mathrm{2}$ \\ a Clinical Pharmacy Department, University Hospital, Montpellier, France \\ ${ }^{\mathrm{b}}$ PhyMedExp, University of Montpellier, CNRS, INSERM, Montpellier, France \\ c Clinical Research and Epidemiology Unit, University Hospital, Montpellier, France \\ d Endocrinology-Diabetology-Nutrition Department University Hospital, Montpellier, France \\ e IRCM -INSERM U1194, University of Montpellier, Montpellier, France
}

Keywords:

Type 2 diabetes

Low-density lipoprotein cholesterol

Cardiovascular risk

Lipid-lowering therapy

\begin{abstract}
A B S T R A C T
Background: Cardiovascular diseases are the first cause of mortality in patients with diabetes, and LDL-cholesterol is a well-established cardiovascular risk factor. This study aimed to assess rate of LDL-cholesterol target attainment among patients with diabetes at very-high cardiovascular risk treated with statins, and to identify predictive factors of non-attainment of target in this population.

Methods: Patients were recruited in the Nutrition-Diabetes unit of Montpellier University Hospital, France, from 2014 to 2017. We included all consecutive patients with type 1 or type 2 diabetes receiving statin treatment and at very-high cardiovascular risk according to 2016 ESC guidelines, therefore having a LDL-cholesterol target of $<1.8 \mathrm{mmol} / \mathrm{L}$. LDL-cholesterol levels were measured upon admission. Variables independently associated with non-attainment of LDL-Cholesterol target were assessed using multivariable logistic regression.

Results: 654 patients were included. Mean age was 63.8 years (SD 11.0), $41.9 \%$ were women and $42.3 \%$ had a history of cardiovascular disease. $59 \%$ of patients did not achieve LDL-cholesterol target, with a median value (interquartile range) of $2.4 \mathrm{mmol} / \mathrm{L}(2.1-2.9)$ versus $1.4 \mathrm{mmol} / \mathrm{L}(1.1-1.6)$ in patients at target. Risk of non-attainment of LDL-cholesterol target value was increased in women (odds ratio [95\% confidence interval]: 2.27 [1.62-3.17]) and decreased in patients with history of coronary artery disease $(0.64$ [0.45-0.89]) or history of stroke or transient ischemic attack (0.59 [0.33-1.07]).

Conclusions: Management of dyslipidemia is suboptimal, even in very-high risk patients with diabetes under statins. Lipid-lowering treatment should be intensified, in particular in very high risk patients with diabetes who are women or in primary cardiovascular prevention.

Clinical Trial number: NCT03449784
\end{abstract}

\section{Introduction}

Cardiovascular diseases (CVD) are the leading cause of death in Europe, responsible for $45 \%$ of all deaths [1], and adults with diabetes mellitus (DM) are two to four times more likely to die from heart

\footnotetext{
* Corresponding author at: Clinical Pharmacy Department, University Hospital, 191 avenue du doyen Gaston Giraud, 34295 Montpellier, France.

E-mail address: c-breuker@chu-montpellier.fr. (C. Breuker).

1 These authors contributed equally to this work.

2 This author takes responsibility for all aspects of the reliability and freedom from bias of the data presented and their discussed interpretation.
}

diseases than those without DM [2]. LDL-cholesterol (LDL-C) is one of the major risk factors for CVD, through its role in the development of atherosclerosis. The efficacy of statins has been demonstrated by a considerable amount of literature not only in lowering LDL cholesterol levels [3] but also in reducing cardiovascular (CV) events, both in DM and non-DM patients [4]. Their efficacy is favored by more-intensive treatment [5]. A meta-analysis of 14 randomized trials, evaluating the efficacy of cholesterol-lowering therapy in 18,686 people with DM, showed that for each $1.0 \mathrm{mmol} / \mathrm{L}$ reduction in LDL-C obtained with statins, risk of major vascular events significantly decreased by $21 \%$, risk of coronary events by $22 \%$ and risk of vascular mortality by $13 \%$ [6]. Guidelines for the management of dyslipidemia have emerged from different countries [7-10]. If CV risk classification slightly differs 
between guidelines, all of them - including the latest French recommendations - defined a target of $\mathrm{LDL}-\mathrm{C}<1.8 \mathrm{mmol} / \mathrm{L}$ for very high risk patients. However, studies revealed an important gap between LDL-C target and LDL-C levels measured in different populations, particularly in very high risk patients. The DYSIS II study carried out in 18 countries showed that target value was reached by only $29.4 \%$ of patients with stable coronary heart disease and $18.9 \%$ of patients suffering from an acute coronary syndrome [11]. DYSIS II study showed that patients with type 2 DM were more likely to achieve targets than others [11]. However, LDL-C goal attainment has rarely been assessed specifically in DM population, in which CVD is of particular importance. This study aimed to assess the rate of LDL-C target value attainment $(<1.8$ $\mathrm{mmol} / \mathrm{L}$ ) among patients at very-high CV risk with DM, and to identify predictive factors of non-attainment of target in this population.

\section{Material and methods}

\subsection{Study design, setting and participants}

This observational study was carried out over a 3-year period from May 2014 to May 2017 in the Diabetes-Nutrition unit of the University Hospital of Montpellier - France. All consecutive adult diabetic patients admitted to that unit during the study period were assessed for eligibility. We included patients with type 1 or $2 \mathrm{DM}$ who received statin treatment for at least three months, had at least one fasting blood lipid profile available during hospitalization, and were classified at very high risk according to the last ESC guidelines [7]. Patients with DM were considered at very high CV risk when they had a major risk factor such as smoking, hypertension or dyslipidemia, or a target organ damage such as proteinuria [7]. Patients were considered as having DM if they were currently on diabetes therapy. Patients with fibrate treatment were not included. Patients with endstage renal disease (stage 5 chronic kidney disease) were not included due to the lack of evidence of statin treatment for $\mathrm{CV}$ management in this population. Patients with elevated triglycerides $(>4.5 \mathrm{mmol} / \mathrm{L}$ ) were excluded due to the impossibility of using the Friedewald formula.

Our observational study follows the World Medical Association's Declaration of Helsinki and meets the requirements of the MR003 procedure of the "Commission Nationale de l'Informatique et des Libertés" (compliance statement $\mathrm{N}^{\circ} 1984895$ ). Indeed, this study was strictly observational as all treatments, examinations and blood samples were performed in routine medical care. As such, the study served to comprehensively document current practices in patients with DM.

\subsection{Data collection}

Data on age, sex, tobacco smoking, body mass index, hypertension (treatment of previously diagnosed hypertension or blood values $>140 / 90 \mathrm{~mm} \mathrm{Hg}$ ), presence and type of CVD (coronary artery disease (CAD), stroke and transient ischemic attack (TIA), peripheral arterial disease), were collected at admission. $\mathrm{LDL}-\mathrm{C}$ levels were calculated with the Friedewald formula, and glomerular filtration rate according to the CKD-EPI formula. Blood samples were taken within $24 \mathrm{~h}$ of hospitalization admission. Microalbuminuria, diabetic retinopathy and CVD definitions and diagnosis were conform to ADA guidelines [12].

Information on the name and daily dose of lipid lowering drugs (statins and/or ezetimibe) at admission was documented. Statin intensity was classified in three categories according to expected LDL-C reductions: high (rosuvastatin $20 \mathrm{mg}$, atorvastatin 40 and $80 \mathrm{mg}$ by day), moderate (rosuvastatin 5 and $10 \mathrm{mg}$, atorvastatin 10 and $20 \mathrm{mg}$, fluvastatin $80 \mathrm{mg}$, simvastatin 20 and $40 \mathrm{mg}$, pravastatin $40 \mathrm{mg}$ by day) and low intensity (pravastatin 10 and $20 \mathrm{mg}$, fluvastatin $40 \mathrm{mg}$ and simvastatin $10 \mathrm{mg}$ by day) for respectively expected reduction of $\geq 50 \%, 30-49 \%$ and $<30 \%$, according to ESC guidelines $[7,13]$. Data were collected by clinical pharmacist.

\subsection{Cardiovascular risk classification and LDL-C target value attainment}

CV risk level and LDL-C target values were defined according to 2011 and 2016 ESC guidelines [7,13]. Both 2011 and 2016 guidelines have been used because the 2016 update has been published during our inclusion period. Proportion of very high-risk patients and LDL-C target attainment were compared between 2011 and 2016 ESC guidelines. Patients classified as being at very high-risk had LDL-C target values of $<1.8 \mathrm{mmol} / \mathrm{L}$. The distance to the LDL-C target was calculated for patients who did not achieve target value.

\subsection{Factors associated with not reaching $L D L-C$ target}

Patients were divided into two subgroups depending on whether they achieved LDL-C target $(<1.8 \mathrm{mmol} / \mathrm{L})$ or not $(\geq 1.8 \mathrm{mmol} / \mathrm{L})$. The following variables were thus considered: age, sex, BMI, history of CVD (CAD, stroke or TIA, peripheral artery disease), HDL-C level, statin intensity (low vs moderate intensity and low vs high intensity) and ezetimibe treatment.

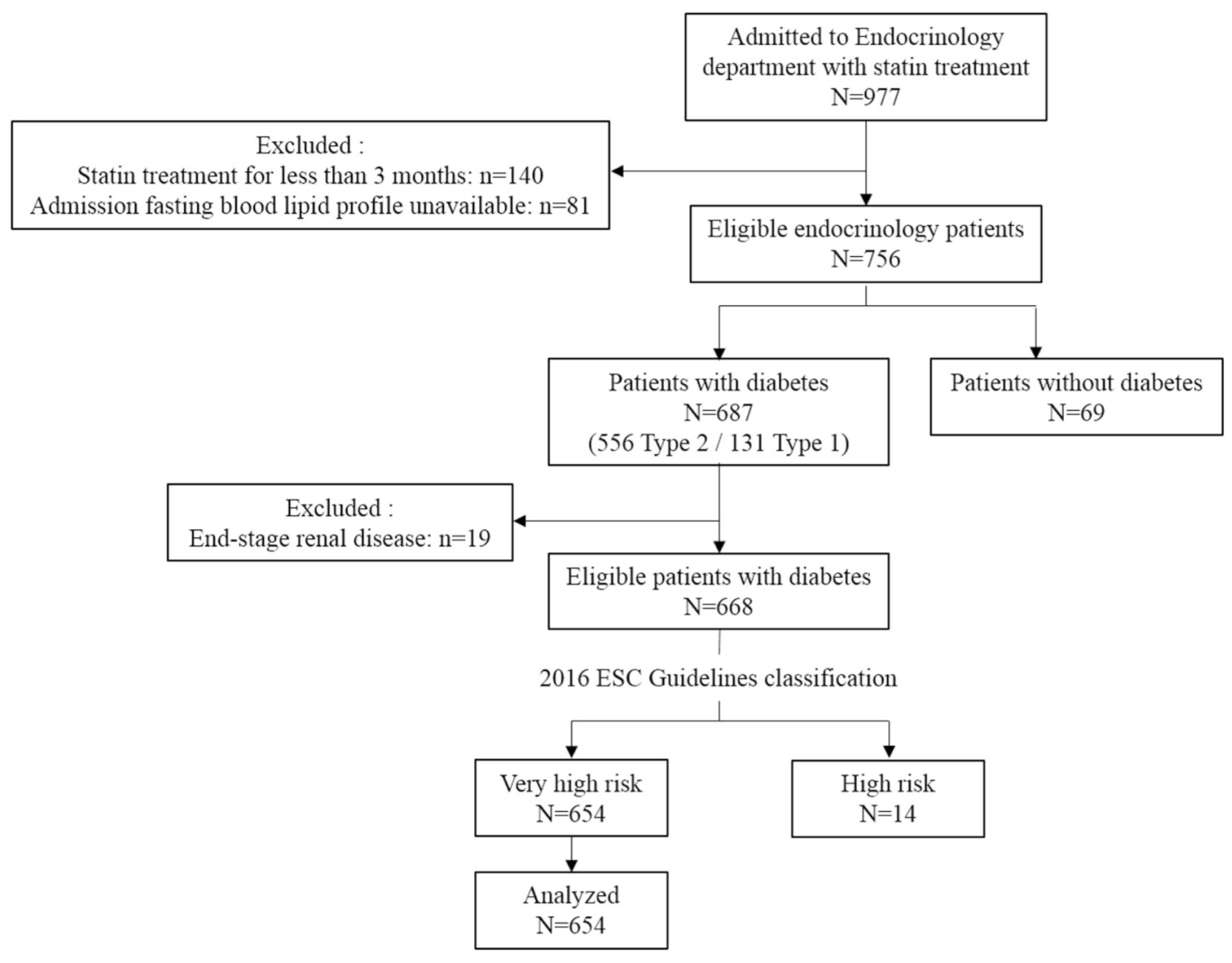

Fig. 1. Flow chart of the study population. 
Patients' characteristics were described with proportions for categorical variables and with means \pm standard deviations $(\mathrm{SD})$ for quantitative variables.

Factors associated with non-attainment of LDL-C target values were first analyzed using the Student $t$-test or the Mann-Whiney $U$ test for continuous variables, and with Chi square or Fisher exact test for categorical variables. We then assessed these relations using univariate and multivariable logistic regression analysis. Variables entered in the multivariable model were those with a $p$-value $<0.2$ in univariate analysis, as well as the variables of clinical interest (ie: age, gender, BMI, history of CAD, history of stroke and TIA, history of peripheral arterial disease, DM type, HDL-C $<1.2 \mathrm{mmol} / \mathrm{L}$ and intensity of statin treatment at admission). Only those factors with multivariable $p$-value $<0.1$ were finally retained in the model using a backward stepwise selection procedure.

Statistical analyses were performed at the conventional two-tailed $\alpha$ level of 0.05 using SAS version 9.1 (SAS Institute, Cary, North Carolina).

\section{Results}

\subsection{Patients' characteristics}

During the study period, 756 patients admitted to our department received statin treatment for $>3$ months and had available blood lipid profile (Fig. 1). Among them, we analyzed all patients with DM and without end-stage renal disease classified at very high risk according to 2016 guidelines $(N=654)$. The population is described in Table 1 . Mean age was 63.8 years (SD 11.0) and $41.9 \%$ were women. In total, $42.3 \%$ had a history of CVD, 38.7\% had diabetic retinopathy, $47.1 \%$ microalbuminuria, and $60.7 \%$ had hypertension. They were mainly admitted for management of their diabetes. Median LDL-C value was 2.0 $\mathrm{mmol} / \mathrm{L}$ (interquartile range $1.5-2.5$ ) and most common statin treatment was of moderate intensity (74.5\%) (Table 2).

\subsection{LDL-C target value attainment}

In total respectively 266 (41\%), 230 (35\%) and 158 patients (24\%) had a LDL-C value $<1.8 \mathrm{mmol} / \mathrm{L}$, between 1.8 and $2.5 \mathrm{mmol} / \mathrm{L}$ and $\geq 2.5$ $\mathrm{mmol} / \mathrm{L}$. Respectively 641 and 654 patients were classified at very high risk according to ESC 2011 or 2016 guidelines, corresponding to $98 \%$ homology between guidelines. Rate of non-achievement of LDL-C target value and mean distance to target value are similar when using either 2016 or 2011 guidelines (Table 2): 59\% of our very-high risk population did not reach target values $(1.8 \mathrm{mmol} / \mathrm{L})$ at admission. Median LDL-C concentration was $2.4 \mathrm{mmol} / \mathrm{L}$ (interquartile range $2.1-2.9$ ) among patients not achieving target versus $1.4 \mathrm{mmol} / \mathrm{L}$ (interquartile range 1.1-1.6) in patients achieving target (Table 3).

Table 1

Patients characteristics.

\begin{tabular}{ll}
\hline$N=654$ & $\mathrm{~N}(\%)$ or mean $\pm \mathrm{sd}$ \\
\hline Age, years & $63.8 \pm 11.0$ \\
Female & $274(41.9)$ \\
BMI, kg/m² & $30.9 \pm 7.0$ \\
Current smoker & $115(17.6)$ \\
Cardiovascular disease & $277(42.3)$ \\
$\quad$ Coronary artery disease & $216(33.0)$ \\
$\quad$ Stroke and transient ischaemic attack & $51(7.8)$ \\
Peripheral arterial disease & $85(13.0)$ \\
Hypertension & $397(60.7)$ \\
Type 1 diabetes & $127(19.4)$ \\
Type 2 diabetes & $527(80.6)$ \\
Diabetic retinopathy & $253(38.7)$ \\
Microalbuminuria & $308(47.1)$ \\
GFR & \\
$60-89 \mathrm{~mL} / \mathrm{min} / 1.73 \mathrm{~m}^{2}$ & $175(26.8)$ \\
$30-59 \mathrm{~mL} / \mathrm{min} / 1.73 \mathrm{~m}^{2}$ & $165(25.2)$ \\
$15-29 \mathrm{~mL} / \mathrm{min} / 1.73 \mathrm{~m}^{2}$ & $42(6.4)$ \\
\hline
\end{tabular}

BMI: body mass index; GFR: glomerular filtration rate.
Table 2

Lipid-lowering treatments, lipid levels and target value attainment at admission.

\begin{tabular}{ll}
\hline $\mathrm{N}=654$ & $\mathrm{~N}(\%)$ or median (IQR) \\
\hline Lipid-lowering treatments & \\
Statin treatment at admission & $122(18.7)$ \\
$\quad$ High-intensity statin treatment & $487(74.5)$ \\
$\quad$ Moderate-intensity statin treatment & $45(6.9)$ \\
$\quad$ Lower-intensity statin treatment & $59(9.0)$ \\
Ezetimibe treatment & \\
Lipid levels & $4.0(3.3-4.6)$ \\
Total cholesterol, mmol/L & $2.0(1.5-2.5)$ \\
LDL-C, mmol/L & $1.1(0.9-1.4)$ \\
HDL-C, mmol/L & $371(56.7)$ \\
HDL-C $<1.2$ mmol/L & $1.6(1.2-2.2)$ \\
Triglycerides, mmol/L & \\
LDL-C target value attainment (<1.8 mmol/L) & \\
No target value attainment/very high risk patients & $379 / 641(59.1)$ \\
$\quad$ ESC 2011 & $388 / 654(59.3)$ \\
ESC 2016 & \\
Distance to target value, mmol/L & $0.6(0.3-1.1)$ \\
ESC 2011 & $0.6(0.3-1.1)$ \\
ESC 2016 & \\
\hline
\end{tabular}

\subsection{Factors associated with non-attainment of LDL-C target}

Characteristics of patients reaching or not LDL-C target value are compared in Table 3. Patients not reaching target value were more often women and had higher triglycerides and HDL-C values. They had less frequently history of CVD, such as CAD and peripheral arterial disease, and received less frequently high-intensity statin treatment (15.2\% vs $23.7 \%$ ) as compared with patients reaching LDL target. Multivariable analysis showed that women and patients with no history of CAD or no history of stroke or TIA had an increased risk of nonattainment of LDL-C target value (Table 3 ).

\section{Discussion}

To our knowledge, this study is the first to assess not only LDL-C target value attainment but also to determine predictors of nonattainment in very high risk patients with DM treated with statins. Our results revealed a high rate of patients not achieving LDL-C target in that population, with $59 \%$ of our patients having LDL-C $\geq 1.8 \mathrm{mmol} /$ $\mathrm{L}$. Moreover, women and patients in primary prevention were less likely to attain LDL-C target.

We found that $59 \%$ of our patients with DM receiving statin treatment had LDL-C $\geq 1.8 \mathrm{mmol} / \mathrm{L}$, despite their very high CV risk profile. This corroborates findings reported in other populations. In DYSIS II study, carried out in patients receiving statin or not, only $29.4 \%$ of patients with stable coronary heart disease and $18.9 \%$ of patients suffering from an acute coronary syndrome reached the LDL-C target of $<1.8$ $\mathrm{mmol} / \mathrm{L}$ [11]. The MONA LISA study carried out in the French general population showed that among the very-high risk subgroup, only $4.2 \%$ attained LDL-C target [14]. In patients with CAD included across Europe in the EUROASPIRE IV study, LDL-C target attainment was $28 \%$ among patients with previously known diabetes and $18 \%$ among patients with newly diagnosed DM [15], and these rates were even lower in the previous EUROASPIRE studies [16]. Although diabetes has been associated with better LDL-C control $[11,15]$, our study revealed suboptimal LDL-C management in very high risk patients with DM. Nevertheless, benefits of controlling this well-known CV risk factor are wellestablished, as LDL-C lowering reduces sharply CV events and mortality, including in patients with DM $[4,6]$. International guidelines for management of dyslipidemia in very high risk patients are clear and consistent. However in France, until the last update in 2017 [10], previous recommendations for dyslipidemia treatment dated back 15 years. As they were no longer up to date, they had been retracted [17]. 


\begin{tabular}{|c|c|c|c|c|c|c|}
\hline & \multirow{2}{*}{$\begin{array}{l}\text { LDL-C at target } \\
N=266\end{array}$} & \multirow{2}{*}{$\frac{\text { LDL-C not at target }}{N=388}$} & \multicolumn{2}{|l|}{ Univariate analysis } & \multicolumn{2}{|c|}{ Multivariate analysis $^{\mathrm{a}}$} \\
\hline & & & OR $(95 \% \mathrm{CI})$ & $p$ & $\mathrm{OR}(95 \% \mathrm{CI})$ & $p$ \\
\hline Age, years & $66.0(57.0-72.0)$ & $64.0(56.0-71.0)$ & $0.99(0.98-1.00)$ & 0.14 & & \\
\hline Female & $79(29.7)$ & $195(50.3)$ & $2.39(1.72-3.33)$ & $<0.001$ & $2.27(1.62-3.17)$ & $<0.001$ \\
\hline $\mathrm{BMI}\left(\mathrm{kg} / \mathrm{m}^{2}\right)$ & $29.9(26.01-32.1)$ & $30.8(26.3-35.0)$ & $1.01(0.99-1.03)$ & 0.48 & & \\
\hline Current smoker & $47(17.7)$ & $68(17.5)$ & $0.99(0.66-1.49)$ & 0.96 & & \\
\hline \multicolumn{7}{|l|}{ Lipid profile } \\
\hline Total cholesterol (mmol/L) & $3.2(2.8-3.6)$ & $4.5(4.0-5.0)$ & - & - & & \\
\hline $\mathrm{LDL}-\mathrm{C}(\mathrm{mmol} / \mathrm{L})$ & $1.4(1.1-1.6)$ & $2.4(2.1-2.9)$ & - & - & & \\
\hline Deviation from target value $(\mathrm{mmol} / \mathrm{L})$ & $-0.4(-0.6$ to -0.2$)$ & $0.6(0.3-1.1)$ & - & - & & \\
\hline Deviation from target value (\%) & $-22.9(-35.7$ to -11.4$)$ & $32.8(15.7-61.4)$ & - & - & & \\
\hline $\mathrm{HDL}-\mathrm{C}(\mathrm{mmol} / \mathrm{L})$ & $1.0(0.8-1.4)$ & $1.1(1.0-1.4)$ & $3.05(1.24-7.5)$ & 0.015 & & \\
\hline $\mathrm{HDL}-\mathrm{C}<1.2 \mathrm{mmol} / \mathrm{L}$ & $169(63.5)$ & $202(52.1)$ & $0.62(0.45-0.86)$ & 0.004 & & \\
\hline Triglycerides $(\mathrm{mmol} / \mathrm{L})$ & $1.5(1.0-2.1)$ & $1.7(1.2-2.2)$ & $1.32(1.04-1.67)$ & 0.020 & & \\
\hline Cardiovascular disease & $138(51.9)$ & $139(35.8)$ & $0.52(0.38-0.71)$ & 0.014 & & \\
\hline Coronary artery disease & $108(40.6)$ & $108(27.8)$ & $0.56(0.41-0.78)$ & $<0.001$ & $0.64(0.45-0.89)$ & 0.009 \\
\hline Stroke and transient ischaemic attack & $27(10.2)$ & $24(6.2)$ & $0.58(0.33-1.04)$ & 0.066 & $0.59(0.33-1.07)$ & 0.08 \\
\hline Peripheral arterial disease & $45(16.9)$ & $40(10.3)$ & $0.56(0.36-0.89)$ & 0.0144 & & \\
\hline Hypertension, $\mathrm{n}(\%)$ & $160(60.2)$ & $237(61.1)$ & $1.04(0.76-1.43)$ & 0.81 & & \\
\hline Type 1 diabetes & $47(17.7)$ & $80(20.6)$ & $1.21(0.81-1.81)^{\mathrm{b}}$ & 0.35 & & \\
\hline Microalbuminuria & $126(47.4)$ & $182(46.9)$ & $0.98(0.72-1.34)$ & 0.90 & & \\
\hline $15<\mathrm{GFR}<60 \mathrm{~mL} / \mathrm{min} / 1.73 \mathrm{~m}^{2}$ & $89(33.5)$ & $118(30.4)$ & $0.89(0.65-1.22)$ & 0.47 & & \\
\hline Diabetic retinopathy & $100(42.2)$ & $153(43.5)$ & $1.05(0.75-1.47)$ & 0.76 & & \\
\hline \multicolumn{7}{|l|}{ Statin treatment at admission } \\
\hline High-intensity & $63(23.7)$ & $59(15.2)$ & $0.52(0.26-1.05)^{c}$ & 0.067 & & \\
\hline Rosuvastatin $20 \mathrm{mg}$ & $12(4.5)$ & $11(2.8)$ & & & & \\
\hline Atorvastatin $80 \mathrm{mg}$ & $16(6.0)$ & $16(4.1)$ & & & & \\
\hline Atorvastatin $40 \mathrm{mg}$ & $35(13.2)$ & $32(8.2)$ & & & & \\
\hline Moderate-intensity & $187(70.3)$ & $300(77.3)$ & $0.89(0.47-1.67)^{\mathrm{c}}$ & 0.30 & & \\
\hline Rosuvastatin $10 \mathrm{mg}$ & $35(13.2)$ & $39(10.1)$ & & & & \\
\hline Rosuvastatin $5 \mathrm{mg}$ & $42(15.8)$ & $69(17.8)$ & & & & \\
\hline Atorvastatin $20 \mathrm{mg}$ & $26(9.8)$ & $32(8.2)$ & & & & \\
\hline Atorvastatin $10 \mathrm{mg}$ & $34(12.8)$ & $76(19.6)$ & & & & \\
\hline Fluvastatin $80 \mathrm{mg}$ & $1(0.4)$ & $0(0)$ & & & & \\
\hline Simvastatin $40 \mathrm{mg}$ & $14(5.3)$ & $15(3.9)$ & & & & \\
\hline Simvastatin $20 \mathrm{mg}$ & 25 & 46 (11.9) & & & & \\
\hline Pravastatin $40 \mathrm{mg}$ & 10 & $23(5.9)$ & & & & \\
\hline Lower-intensity & $16(6.0)$ & $29(7.5)$ & 1 & & & \\
\hline Pravastatin $20 \mathrm{mg}$ & $11(4.1)$ & $19(4.9)$ & & & & \\
\hline Pravastatin $10 \mathrm{mg}$ & $1(0.4)$ & $3(0.8)$ & & & & \\
\hline Fluvastatin $40 \mathrm{mg}$ & $0(0)$ & $1(0.3)$ & & & & \\
\hline Simvastatin $10 \mathrm{mg}$ & $4(1.5)$ & $6(1.5)$ & & & & \\
\hline Ezetimibe treatment & $30(11.3)$ & $29(7.5)$ & $0.64(0.37-1.09)$ & 0.098 & & \\
\hline
\end{tabular}

Data are $\mathrm{n}(\%)$ or median (interquartile range).

${ }^{a}$ Model adjusted for sex, age, BMI, cardiovascular disease, myocardial infarction, coronary artery disease, statin treatment intensity (low vs. high).

b Reference category: type 2 diabetes.

${ }^{c}$ Reference category: lower-intensity statin treatment.

We found that being a woman, having no history of CAD or no history of stroke or TIA was associated with lower attainment of LDL-C target. This gender difference has been reported in several studies $[11,18]$ despite no sex-specific recommendations for lipid therapy [19]. It seems to be multifactorial, explained notably by lower prescription, lower adherence and higher discontinuation of statin treatment in women, due to lower provider and patient awareness of CVD risk and higher risk of intolerance $[20,21]$. Patients with no history of CAD or stroke were less likely to achieve LDL-C target, probably because CV risk is underestimated in such patients, inducing less aggressive risk factor management. Yet, any patient with DM is automatically at high or very high CV risk, with no need for risk estimation tools such as the SCORE system [22]. In our study, high versus low-intensity statin treatment tended to be associated with lower risk of non-attaining LDLtarget in univariate analysis, but this trend disappeared after adjustment for other factors, in contrast with previous findings, which reporting a significant effect $[11,23]$. Moreover the 59 (9\%) patients with high-intensity statin treatment who did not attain LDL-target might benefit from additional non-statin therapy such as ezetimibe [24]. Our results are consistent with the available literature suggesting that $\mathrm{CV}$ risk estimation by physicians should be improved. In the ERIKA study carried out among patients free of CVD and with at least one major CVD risk factor, $85 \%$ of physicians reported using clinical guidelines, and main reasons for not using them were inadequate knowledge, time constraints and lack of perceived usefulness [25]. Targeted interventions should therefore be implemented to improve $\mathrm{CV}$ risk management.

A meta-analysis of 15 randomized controlled trials in outpatients with DM showed that interventions of pharmacists, alone or in collaboration with other health care professionals, improved management of major CV risk factors, including LDL-C [26]. Such interventions included medication management, educational interventions to patients and feedback to another health care professional.

Interestingly, CV risk assessment and rate of LDL-C achievement were almost identical when calculated with the current European guidelines [7] or with European guidelines available at the study onset [13].

\section{Study limitations}

Several limits must be acknowledged. First, the monocentric nature of our study might limit the generalizability of our result. Our findings may not apply to any patient with DM as patients enrolled in our university hospital constitute a very high risk population. We did not include outpatients, who may have better diabetes control than our 
patients, admitted to hospital mainly for management of their diabetes. Socio-economic level and non-adherence to statin treatment may be predictive factors of non-attainment of lipid targets but they have not been collected in our study. Moreover, we do not know whether patients admitted to hospital were followed by a general practitioner or by a cardiology or endocrinology specialist. Nevertheless, a key strength of the present study is that admission LDL-C values have been measured from blood samples taken within $24 \mathrm{~h}$ of admission, while previous studies often used available lipid analyses performed in the previous months.

\section{Conclusion}

This study extends current knowledge about the gap between recommended and observed LDL-C levels by providing evidence of this gap in very high CV risk patients with DM. Such findings have a number of practical implications. They highlight the need for optimized lipid lowering treatment to ensure risk factor management in this very high risk population. More specifically, greater efforts should be made in patients with DM who are women or in primary prevention, as their CV risk may currently be underestimated. Indeed, statin efficacy to reduce LDL-C levels and risk of CVD is well established even in this population.

\section{Acknowledgement of grant support}

None.

\section{Conflicts of interest}

None.

\section{References}

[1] N. Townsend, M. Nichols, P. Scarborough, M. Rayner, Cardiovascular disease in Europe-epidemiological update 2015, Eur. Heart J. 36 (40) (2015) 2696-2705.

[2] American Heart Association, Cardiovascular disease and diabetesupdated 29 January 2018. Available from: http://www.heart.org/HEARTORG/Conditions/More/Diabetes/WhyDiabetesMatters/Cardiovascular-Disease-Diabetes_UCM_313865_Article. jsp 2015.

[3] M.G. Silverman, B.A. Ference, K. Im, S.D. Wiviott, R.P. Giugliano, S.M. Grundy, et al., Association between lowering LDL-C and cardiovascular risk reduction among different therapeutic interventions: a systematic review and meta-analysis, JAMA 316 (12) (2016) 1289-1297.

[4] R. Collins, C. Reith, J. Emberson, J. Armitage, C. Baigent, L. Blackwell, et al., Interpretation of the evidence for the efficacy and safety of statin therapy, Lancet 388 (10059) (2016) 2532-2561.

[5] K.C. Koskinas, G.C.M. Siontis, R. Piccolo, D. Mavridis, L. Raber, F. Mach, et al., Effect of statins and non-statin LDL-lowering medications on cardiovascular outcomes in secondary prevention: a meta-analysis of randomized trials, Eur. Heart J. 39 (14) (2017) 1172-1180.

[6] Cholesterol Treatment Trialists C, P.M. Kearney, L. Blackwell, R. Collins, A. Keech, J. Simes, et al., Efficacy of cholesterol-lowering therapy in 18,686 people with diabetes in 14 randomised trials of statins: a meta-analysis, Lancet 371 (9607) (2008) 117-125.

[7] A.L. Catapano, I. Graham, G. De Backer, O. Wiklund, M.J. Chapman, H. Drexel, et al, ESC/EAS guidelines for the management of dyslipidaemias, Eur. Heart J. 37 (39) (2016) 2999-3058.
[8] P.S. Jellinger, Y. Handelsman, P.D. Rosenblit, Z.T. Bloomgarden, V.A. Fonseca, A.J Garber, et al., American Association of Clinical Endocrinologists and American College of Endocrinology Guidelines for Management of Dyslipidemia and Prevention of Cardiovascular Disease, Endocr. Pract. 23 (Suppl. 2) (2017) 1-87.

[9] M. Kirby, R. Rasalam, Managing Dyslipidemia in the Context of Diabetes, vol. 2, Diabetes \& Primary Care Australia, 2017 100-110.

[10] Haute Autorité de Santé, Principales dyslipidémies: stratégies de prise en charge, 2017.

[11] A.K. Gitt, D. Lautsch, J. Ferrieres, G.M. De Ferrari, A. Vyas, C.A. Baxter, et al., Cholesterol target value attainment and lipid-lowering therapy in patients with stable or acute coronary heart disease: results from the dyslipidemia international study II, Atherosclerosis 266 (2017) 158-166.

[12] American Diabetes A. 10, Microvascular complications and foot care: standards of medical care in diabetes-2018, Diabetes Care 41 (Suppl. 1) (2018), S105-S18. .

[13] European Association for Cardiovascular P, Rehabilitation, Z. Reiner, A.L. Catapano, G. De Backer, I. Graham, et al., ESC/EAS guidelines for the management of dyslipidaemias: the Task Force for the management of dyslipidaemias of the European Society of Cardiology (ESC) and the European Atherosclerosis Society (EAS), Eur. Heart J. 32 (14) (2011) 1769-1818.

[14] V. Bongard, J. Dallongeville, D. Arveiler, J.B. Ruidavets, P. Amouyel, A. Wagner, et al., Attainment of low-density lipoprotein cholesterol target in the French general population according to levels of cardiovascular risk: insights from the MONA LISA study, Arch. Cardiovasc. Dis. 106 (2) (2013) 93-102.

[15] V. Gyberg, D. De Bacquer, G. De Backer, C. Jennings, K. Kotseva, L. Mellbin, et al., Patients with coronary artery disease and diabetes need improved management: a report from the EUROASPIRE IV survey: a registry from the EuroObservational Research Programme of the European Society of Cardiology, Cardiovasc. Diabetol. 14 (2015) 133.

[16] K. Kotseva, D. De Bacquer, C. Jennings, V. Gyberg, G. De Backer, L. Ryden, et al., Time trends in lifestyle, risk factor control, and use of evidence-based medications in patients with coronary heart disease in Europe: results from 3 EUROASPIRE Surveys, 1999-2013, Glob. Heart 12 (4) (2017) (315-22 e3).

[17] French Society of Endocrinology, Francophone Society of Diabetes, New French Society of Atherosclerosis, S. Beliard, F. Bonnet, B. Bouhanick, et al., Consensus statement on the management of dyslipidaemias in adults, Diabete Metab. 42 (6) (2016) 398-408.

[18] D. De Smedt, D. De Bacquer, J. De Sutter, J. Dallongeville, S. Gevaert, G. De Backer, et al., The gender gap in risk factor control: effects of age and education on the control of cardiovascular risk factors in male and female coronary patients. The EUROASPIRE IV study by the European Society of Cardiology, Int. J. Cardiol. 209 (2016) 284-290.

[19] M. Gulati, Merz C.N. Advances in Lipid Therapy, The role of lipid treatment in women in primary prevention, Prog. Cardiovasc. Dis. 59 (2) (2016) 178-189.

[20] K.M. Goldstein, L.L. Zullig, L.A. Bastian, H.B. Bosworth, Statin adherence: does gender matter? Curr Atheroscler Rep 18 (11) (2016) 63.

[21] M.W. Schoen, R.G. Tabak, J. Salas, J.F. Scherrer, F.R. Buckhold, Comparison of adherence to guideline-based cholesterol treatment goals in men versus women, Am. J. Cardiol. 117 (1) (2016) 48-53.

[22] R.M. Conroy, K. Pyorala, A.P. Fitzgerald, S. Sans, A. Menotti, G. De Backer, et al., Estimation of ten-year risk of fatal cardiovascular disease in Europe: the SCORE project, Eur. Heart J. 24 (11) (2003) 987-1003.

[23] M.A. Stone, G. Charpentier, K. Doggen, O. Kuss, U. Lindblad, C. Kellner, et al., Quality of care of people with type 2 diabetes in eight European countries: findings from the Guideline Adherence to Enhance Care (GUIDANCE) study, Diabetes Care 36 (9) (2013) 2628-2638.

[24] J.G. Robinson, Nonstatins and proprotein convertase subtilisin/kexin type 9 (PCSK9) inhibitors: role in non-familial hypercholesterolemia, Prog. Cardiovasc. Dis. 59 (2) (2016) 165-171

[25] J. Dallongeville, J.R. Banegas, F. Tubach, E. Guallar, C. Borghi, G. De Backer, et al., Survey of physicians' practices in the control of cardiovascular risk factors: the EURIKA study, Eur. J. Prev. Cardiol. 19 (3) (2012) 541-550.

[26] V. Santschi, A. Chiolero, G. Paradis, A.L. Colosimo, B. Burnand, Pharmacist interventions to improve cardiovascular disease risk factors in diabetes: a systematic review and meta-analysis of randomized controlled trials, Diabetes Care 35 (12) (2012) 2706-2717. 